\title{
Modelagem matemática de forno rotativo de cal de fábrica de celulose
}

\author{
Alves, E. D. ${ }^{1}$; Pinheiro, O. S. ${ }^{2}$; Costa, A. O. S. ${ }^{3}$; Costa Jr, E. F. ${ }^{3}$ \\ 1 Graduando em Engenharia Química \\ 2 Especialista da Celulose Nipo-Brasileira S.A. - CENIBRA \\ 3 Docente do curso de Engenharia Química UFES - Universidade Federal do Espírito Santo, Campus de Alegre, \\ Alegre, ES, Brasil
}

\begin{abstract}
Resumo
O forno rotativo de cal de fábrica de celulose tem como objetivos: reduzir os custos de produtos químicos através da conversão da lama de cal para cal, e resolver o problema do descarte da lama de cal. A energia do forno de cal é proveniente da queima de combustíveis fósseis, sendo que nas fábricas mais modernas utiliza-se gás natural. À exceção deste equipamento, praticamente toda a energia necessária para o funcionamento das fábricas de celulose modernas são provenientes da queima de licor preto ou de biomassa. Desta forma, a mitigação da emissão de gases de efeito estufa em fábricas de celulose está diretamente relacionada com o aumento da eficiência do forno de cal. A modelagem matemática do forno rotativo de cal é baseada em balanços de massa com reações químicas. As entradas do modelo são as composições da lama de cal e do combustível; as vazões de lama de cal, de combustível e ar; a conversão da reação de calcinação e o rendimento das reações paralelas que ocorrem no forno. As saídas do modelo são a quantidade e composição da cal produzida ( $\mathrm{CaO}$ e impurezas) e a vazão e composição do gás de exaustão.
\end{abstract}

Keywords (Palavras chaves): forno rotativo de cal, lama de cal, modelagem.

\section{Introdução}

Um dos principais equipamentos para recuperação dos produtos químicos de um fábrica de celulose é o forno rotativo de cal. Os objetivos deste equipamento são: reduzir os custos de produtos químicos através da conversão da lama de cal (composta principalmente por carbonato de cálcio) para cal (óxido de cálcio), e resolver o problema do descarte da lama de cal.

As fábricas de celulose geralmente utilizam energia proveniente da queima de licor preto (subproduto do cozimento da madeira) ou de biomassa (partes das árvores que não podem ser utilizadas no cozimento) em caldeiras. Entretanto no forno de cal não se utiliza esta biomassa, sendo necessário o emprego de combustíveis fósseis como o óleo ou gás natural. Desta forma, um aumento da eficiência energética no forno de cal, além de possibilitar o aumento da competitividade da empresa, é de extrema importância para a diminuição dos impactos ambientais do setor de produção de celulose.

A lama de cal é um resíduo sólido de coloração cinza claro, homogêneo e sem odor característico, gerado no processo de clarificação do licor verde, sendo a lama de cal processada para a recuperação da cal [1].

Para um bom desempenho do forno de cal, a qualidade da lama de cal enviada ao forno se torna um fator relevante.

\section{Modelagem}

A modelagem matemática do forno rotativo de cal está baseada em balanços de massa com reações químicas. De acordo com a Figura 1, as entradas do forno rotativo de cal são as vazões de lama de cal, de combustível (A1) e ar (A2). As saídas são a cal ( $\mathrm{CaO}$ ) e os gases de exaustão (A3).

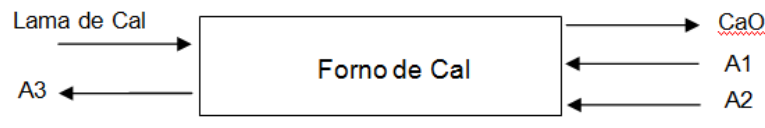

Figura 1: Entradas e saídas do forno rotativo de cal.

Já as entradas do modelo são as composições da lama de cal e do combustível; as vazões de lama de cal, de combustível e ar; a conversão da reação de calcinação, sendo esta, a principal reação que ocorre no forno, e o rendimento das reações paralelas que ocorrem no 
forno. As saídas do modelo são a quantidade e composição da cal produzida ( $\mathrm{CaO}$ e impurezas) e a vazão e composição do gás de exaustão.

\subsection{Composição}

A composição da lama de cal é basicamente carbonato de cálcio $\left(\mathrm{CaCO}_{3}\right)$, mas apresenta algumas impurezas em sua composição, como dióxido de silício (sílica) e óxido de alumínio (alumina) [2]. Na Tabela 1 são apresentados os compostos e a porcentagem presente na lama de cal.

Tabela 1: Composição da lama de cal [2].

\begin{tabular}{ccccc}
\hline Composto & $\mathrm{CaCO}_{3}$ & $\mathrm{SiO}_{2}$ & $\mathrm{Al}_{2} \mathrm{O}_{3}$ & Outros \\
\hline Composição (\%) & 91,5 & 1,5 & 0,5 & 6,5 \\
\hline
\end{tabular}

O gás natural, composto químico formado por átomos de carbono e hidrogênio, é o principal combustível utilizado atualmente em fornos rotativos de cal para a calcinação da lama de cal, pois é um combustível menos poluente por apresentar como produto de combustão o vapor d'água, dióxido de carbono e baixos índices de óxidos de enxofre e fuligem. O principal componente do gás natural é o metano $\left(\mathrm{CH}_{4}\right)$ e o restante de sua composição é formado por etano, propano e outros hidrocarbonetos [3]. Na Tabela 2 é apresentada a composição do gás natural.

Tabela 2: Composição do gás natural [3].

\begin{tabular}{ccccccc}
\hline Composto & $\mathrm{CH}_{4}$ & $\mathrm{C}_{2} \mathrm{H}_{6}$ & $\mathrm{C}_{3} \mathrm{H}_{8}$ & $\mathrm{C}_{4} \mathrm{H}_{10}$ & $\mathrm{CO}_{2}$ & $\mathrm{~N}_{2}$ \\
\hline Composição (\%) & 89 & 6 & 1,8 & 1,0 & 1,5 & 0,7 \\
\hline
\end{tabular}

\subsection{Reações}

A principal reação que ocorre no forno rotativo de cal é a reação de calcinação, apresentada na Equação 1.

$\mathrm{CaCO}_{3} \rightarrow \mathrm{CaO}+\mathrm{CO}_{2}$

Reações paralelas acontecem no forno durante a calcinação, Equações 2, 3 e 4, pois a lama apresenta algumas impurezas, sendo que estas reagem com a cal formada.

$2 \mathrm{CaO}+\mathrm{SiO}_{2} \rightarrow \mathrm{Ca}_{2} \mathrm{SiO}_{4}$

$\mathrm{CaO}+\mathrm{Ca}_{2} \mathrm{SiO}_{4} \rightarrow \mathrm{Ca}_{3} \mathrm{SiO}_{5}$

$3 \mathrm{CaO}+\mathrm{Al}_{2} \mathrm{O}_{3} \rightarrow \mathrm{Ca}_{3} \mathrm{Al}_{2} \mathrm{O}_{6}$

A partir da composição da lama de cal e do gás natural e das equações desenvolveu-se o balanço de massa do forno de cal, no qual foi possível determinar a quantidade de cal produzida $(\mathrm{CaO})$ e suas impurezas ( $\mathrm{Ca}_{2} \mathrm{SiO}_{4}, \mathrm{Ca}_{3} \mathrm{SiO}_{5}, \mathrm{Ca}_{3} \mathrm{Al}_{2} \mathrm{O}_{6}$ e outros ), e a quantidade de gases de exaustão. A composição de saída do forno rotativo de cal, em porcentagem, é apresentada na Tabela 3. Na Tabela 4 encontra-se a composição molar do gás de exaustão.

Tabela 3: Composição de saída do forno rotativo de cal.

\begin{tabular}{cc}
\hline Composto & Composição (\%) \\
\hline $\mathrm{CaO}$ & 94,29 \\
\hline $\mathrm{Ca}_{2} \mathrm{SiO}_{4}$ & 0,034 \\
\hline $\mathrm{Ca}_{3} \mathrm{SiO}_{5}$ & 0,003 \\
\hline $\mathrm{Ca}_{3} \mathrm{Al}_{2} \mathrm{O}_{6}$ & 0,012 \\
\hline Outros & 5,661 \\
\hline
\end{tabular}

Tabela 4: Composição molar do gás de exaustão.

\begin{tabular}{ccccc}
\hline Composto & $\mathrm{CO}_{2}$ & $\mathrm{H}_{2} \mathrm{O}(\mathrm{g})$ & $\mathrm{N}_{2}$ & $\mathrm{O}_{2}$ \\
\hline Composição (\%) & 4,55 & 18,12 & 54,22 & 23,11 \\
\hline
\end{tabular}

\section{Conclusão}

A partir do balanço de massa do forno rotativo de cal é possível determinar a quantidade de cal produzida e suas impurezas, a quantidade de combustível necessário para a queima da lama de cal e a quantidade de gases de exaustão.

\section{Agradecimentos}

Os autores agradecem à FAPES pela bolsa pesquisador capixaba e pela bolsa de iniciação científica e ao CNPq pela bolsa de produtividade DTI.

\section{Referências}

[1] MAEDA, S., COSTA, E. R. O., SILVA, H. D.. Uso de Resíduos da Fabricação de Celulose e Papel e da Reciclagem de Papel. Dados eletrônicos. Colombo: Embrapa Florestas, 2010.

[2] REIS, H. M.; MACEDO, J. C. F.; SILVA, R.J.. Análise da cinética química da reação de calcinação da lama de cal gerada no ciclo de recuperação química na indústria de extração de celulose pelo processo Kraft. COBEQ. 2010.

[3] Gasmig - Companhia de Gás de Minas Gerais, Minas Gerais. Disponível em <http://www.gasmig.com.br/Gas/Composicao.aspx>. Acesso em: 07 Maio 2014. 